\title{
The Power of Options: The Solution for Healthier Society and
}

\section{Better Economy}

\author{
Dr. Saleh A. S. AL-Abdulhadi ${ }^{{ }^{*}}$ \\ ${ }^{1}$ Assistant Professor \& Consultant, Medical Molecular Genetic, Founder and Chairman of Medical \\ Molecular Genetic Unit, Head of Medical Genetic Division, Department of Medical Laboratory \\ Sciences, College of Applied Medical Sciences, Prince Sattam bin Abdulaziz University, Saudi Arabia \\ *Dr. Saleh A. S. AL-Abdulhadi, E-mail: dr.salehalabdulhadi@gmail.com
}

Received: October 22, 2017 Accepted: November 2, 2017 Online Published: November 15, 2017

doi:10.22158/rhs.v2n4p350 URL: http://dx.doi.org/10.22158/rhs.v2n4p350

\begin{abstract}
Preimplantation Genetic Diagnosis (PGD) testing is the practice of obtaining a cellular biopsy sample from a developing human oocyte or embryo, acquired via a cycle of In Vitro Fertilization (IVF); evaluating the genetic composition of this sample; and using this information to determine which embryos will be optimal for subsequent uterine transfer. PGD has become an increasingly useful adjunct to IVF procedures. The ability to provide couples who are known carriers of genetic abnormalities the opportunity to deliver healthy babies has opened a new frontier in reproductive medicine. The purpose of the PGD is enables us to choose which embryos will be implanted into the mother. In the present study we investigate the frequency of application of this technique in the kingdom and GCC to find out, the population awareness of these technique and the advantages which could apply to the community. We also interested to know frequencies of centers and studies in this field. This epidemiological study helps to improve social awareness and community services toward reducing frequencies of genetic disorders.
\end{abstract}

\section{Keywords}

Preimplantation Genetic Diagnosis (PGD), In Vitro Fertilization (IVF), biopsy, Saudi Arabia

\section{Introduction}

Preimplantation Genetic Diagnosis (PGD) is a new method used mainly for those who have high risk for transmitted genetic diseases to their children (Asscher \& Koops, 2010) whatever they diagnosed with certain transmitted disease as adults or have a family history for transmitted disease. Also it can used for patients who have suffer of recurrent miscarriages (Asscher \& Koops, 2010), unsuccessful IVF cycles (Asscher \& Koops, 2010) and sever male factor infertility (Asscher \& Koops, 2010). It is available for a large number of monogenic disorders due to a single gene only (autosomal recessive, autosomal dominant or X-linked) or of chromosomal structural aberrations. This helps these couples to 
identify embryos carrying a genetic disease or a chromosome abnormality, thus avoiding diseased offspring (Asscher \& Koops, 2010). The most frequently diagnosed autosomal recessive disorders are cystic fibrosis, Beta-thalassemia, sickle cell disease and spinal muscular atrophy type 1 . The most common dominant diseases are myotonic dystrophy, Huntington's disease and Charcot-Marie-Tooth disease; and in the case of the $\mathrm{X}$-linked diseases, most of the cycles are performed for fragile $\mathrm{X}$ syndrome, haemophilia A and Duchenne muscular dystrophy (Basille, 2009).

Edwards and Gardner preformed first known embryo biopsy in 1968 on rabbits (Bellavia, 2010). Then used in human first in United Kingdom along with PGD in the mid-1980s as alternative to prenatal diagnoses. In the beginning, PGD revolved to a new level where it can indirectly determine the gender of embryo and then they used it for avoiding X-linked diseases (Asscher \& Koops, 2010). The first unaffected child born by using PGD were in 1989 in London and reported by Handyside and his groups, and they obtained the genetic sample from the cleavage stage and they also used PGD to an X-linked disease (Handyside, 1990). In addition, they used Polymerase Chain Reaction (PCR) method to detect segment of Y-chromosome. Nowadays, there is many hospitals doing PGD and in Saudi Arabia, there is more than 1600 cases done with PGD in King Faisal Specialist Hospital and Research Centre (Debrock, 2010).

PGD also can be used to select embryos to be without a genetic disorder, to have increased chances of successful pregnancy, to match a sibling in HLA type in order to be a donor, to have less cancer predisposition, and for sex selection (Dumoulin, 1998).

Preimplantation Genetic Profiling (PGP) has been suggested as a method to determine embryo quality in in vitro fertilization, in order to select an embryo that appears to have the greatest chances for successful pregnancy (Figure 1) (Hardarson, 2008). However, as the results of PGP rely on the assessment of a single cell, PGP has inherent limitations as the tested cell may not be representative of the embryo because of mosaicism (Hardarson, 2008).

Human Leukocyte Antigen (HLA) typing of embryos, so that the child's HLA matches a sick sibling, availing for cord-blood stem cell donation (Hardarson, 2008). The child is in this sense a "savior sibling" for the recipient child (Hardarson, 2008).

A more recent application of PGD is to diagnose late-onset diseases and cancer, such as Huntington disease (Asscher \& Koops, 2010). Since affected individuals remain healthy until the onset of the disease, frequently in the fourth decade of life (Asscher \& Koops, 2010).

Preimplantation Genetic Diagnosis provides a method of prenatal sex discernment even before implantation, and may therefore be termed preimplantation sex discernment. Potential applications of preimplantation is sex discernment in gene testing for monogenic disorders whose presentation is linked to the sex, such as $\mathrm{X}$-linked diseases.

The idea of PGD is to do test before pregnancy occur, these to avoid any chance of have baby with an affected genetic disorders. This procedure can be done in in three main stages: the oocyte and zygote stage (occur in day 0 and day 1) via polar body biopsy; the cleavage stage (day 3) employing 
blastomere biopsy; the blastocyst stage (day 5 andlor day 6) utilizing trophectoderm biopsy (Figure 2) (Harper, 2001). All of these method aims to obtain genetic samples from oocyte and embryo by breaching the surrounding membrane (Table 1) (Harper, 2001). And after obtaining the samples we use two methods which is polymerase chain reaction (PCR) and Fluorescence in situ hybridization (FISH) to search for genetic disorders (Figure 3) (Asscher \& Koops, 2010). There some changes happened to the PGD technique like using calcium magnesium free as a media found to be better in reducing lysis of blastomere (Harper, 2012). There is also some disadvantages when we using PGD test. There have been a number of misdiagnoses for some cases and beside the diagnoses issues the PGD technique is an expensive method witch required a lot of money especially in countries like UK where the prenatal diagnoses paid for by the state but not PGD (Basille, 2009). And we must not forget the paint part, that will defiantly suffer from going through IVF and that will cost them a lot of money and make them stressful (Asscher \& Koops, 2010).

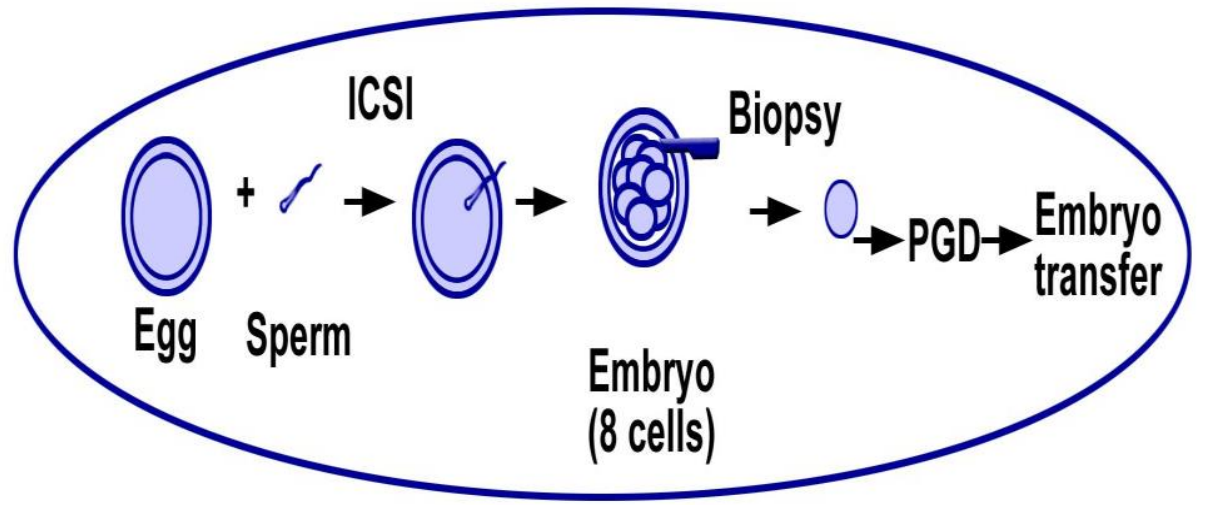

Figure 1. PGD Process
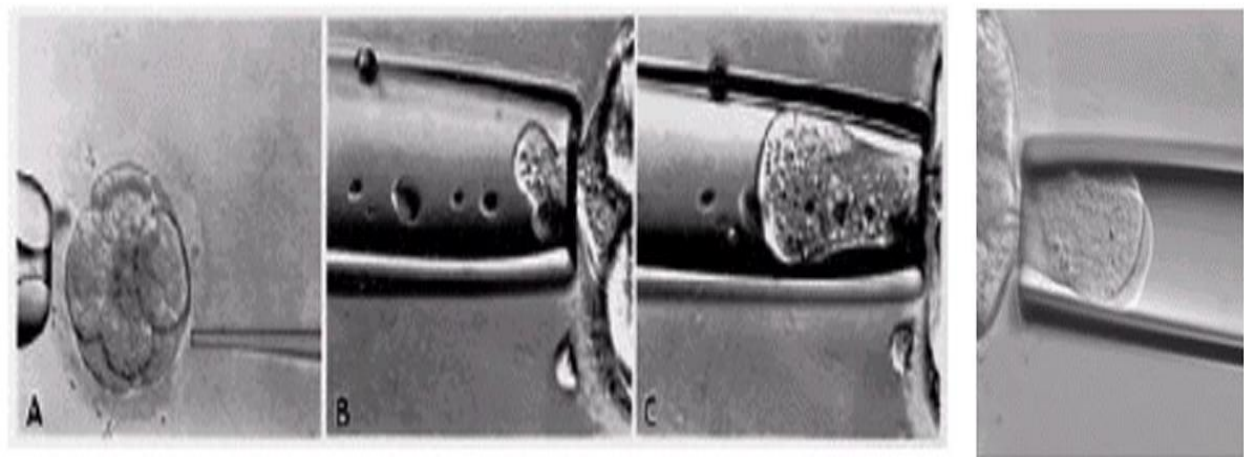

Figure 2. Removal of Blastomere from 8 Cell Embryo (Blastocyst) 
Table 1. PGD Methods for Obtaining Genetic Samples from Oocyte and Embryo by Breaching the Surrounding Membrane

\begin{tabular}{|c|c|c|c|}
\hline & Polar bodies & Cleavage stage & Blastocyst stage \\
\hline Advantages & $\begin{array}{l}\text { The sample obtained early } \\
\text { Which allow IFV laboratory } \\
\text { maximum flexibility in terms } \\
\text { of embryo transfer. }\end{array}$ & $\begin{array}{l}\text { This method allow testing } \\
\text { both maternal and paternal } \\
\text { genetic contribution to the } \\
\text { embryo. }\end{array}$ & $\begin{array}{l}\text { The biopsy appears to } \\
\text { have little if any impact } \\
\text { on subsequent embryo } \\
\text { development and the high } \\
\text { number of cells obtained } \\
\text { result in an improved } \\
\text { accuracy of genetic test. }\end{array}$ \\
\hline Disadvantages & $\begin{array}{l}\text { The information obtained is } \\
\text { related to mother only, No } \\
\text { abnormalities of paternal origin } \\
\text { can be detected. }\end{array}$ & $\begin{array}{l}\text { The fragile of cleavage } \\
\text { stage embryo, which } \\
\text { require highly skilled } \\
\text { embryologists. }\end{array}$ & $\begin{array}{l}\text { Many patients do not } \\
\text { produce sufficient } \\
\text { numbers of high quality } \\
\text { embryos to be considered } \\
\text { for culture. }\end{array}$ \\
\hline
\end{tabular}

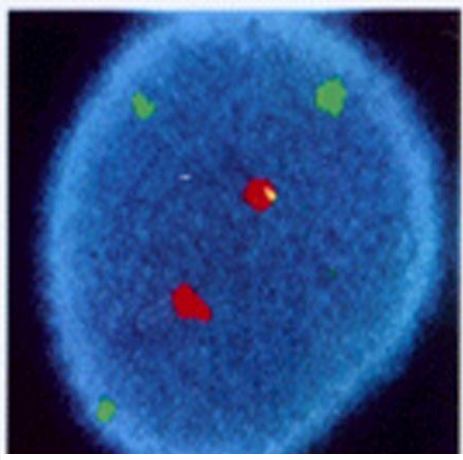

Trisomy 13

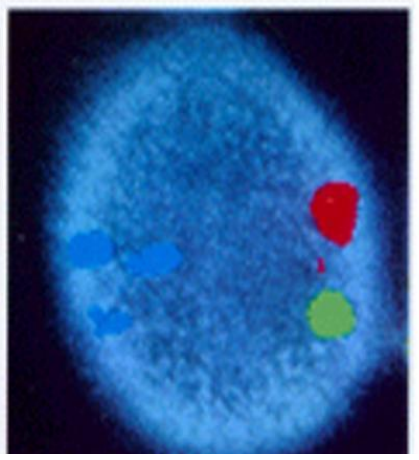

Trisomy 18

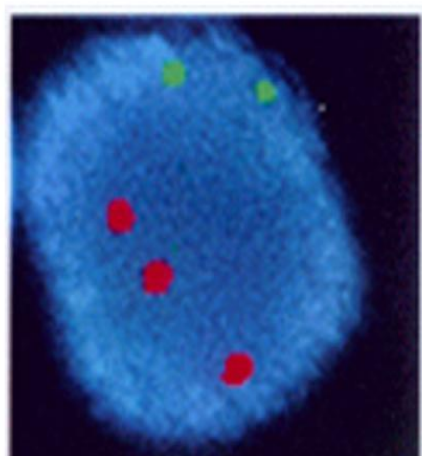

Trisomy 21

Figure 3. Abnormalities of Chromosome 13, 18, 21

\section{Material and Method}

\subsection{Bioinformatics}

Bioinformatics is the application of computer technology to the management of biological information. Computers are used to gather, store, analyze and integrate biological and genetic information which can then be applied to gene-based drug discovery and development. The need for Bioinformatics capabilities has been precipitated by the explosion of publicly available genomic information resulting from the Human Genome Project. 


\subsection{Statistical Analysis}

We used descriptive statistics, which is the discipline of quantitatively describing the main features of a collection of information (Asscher \& Koops, 2010), or the quantitative description itself. It is distinguished from inferential statistics (or inductive statistics), in that descriptive statistics aim to summarize a sample, rather than use the data to learn about the population that the sample of data is thought to represent. This generally means that descriptive statistics, unlike inferential statistics, are not developed on the basis of probability theory (Basille, 2009; Bellavia, 2010). Even when a data analysis draws its main conclusions using inferential statistics, descriptive statistics are generally also presented. It also provides simple summaries about the sample and about the observations that have been made. Such summaries may be either quantitative, summary statistics, or visual (Handyside, 1990).

\section{Results}

\subsection{Literature Review}

In the literature, we found out that the indications for Preimplantation Genetic Screening, are mostly in early pregnancy losses and this can be attributed to aneuploidy. Primary candidates for PGS can include women of advanced maternal age, couples with history of recurrent pregnancy loss, couples with repeated IVF failure, and male partner with severe male factor infertility.

These patient populations are at risk of failure with IVF because of a high proportion of aneuploid embryos. PGD is believed to decrease this risk by selecting chromosomally normal embryos that have a higher chance of implantation.

\subsubsection{Advanced Maternal Age}

The risk of aneuploidy in children increases as women age. The chromosomes in the egg are less likely to divide properly, leading to an extra or missing chromosome in the embryo (Table 2). One of the most frequent aneuploidies, is trisomy of chromosome 21, which leads to Down syndrome (Table 3).

Table 2. Chromosomal Abnormalities

\begin{tabular}{llll}
\hline Age, y & Embryos (Normal), \% & Embryos (Aneuploidy), \% & Other Abnormality, \% \\
\hline $25-35$ & 61 & 8 & 31 \\
$36-37$ & 60 & 10 & 30 \\
$38-39$ & 47 & 18 & 35 \\
$40-41$ & 43 & 26 & 31 \\
$42-44$ & 39 & 30 & 31 \\
\hline
\end{tabular}


Table 3. Frequency of Down Syndrome Per Maternal Age

\begin{tabular}{lll}
\hline Age, y & $\begin{array}{l}\text { Frequency of Fetuses With Down Syndrome/ } \\
\text { Normal Fetuses at } 16 \text { Weeks of Pregnancy }\end{array}$ & $\begin{array}{l}\text { Frequency of Live Births of Babies/ } \\
\text { With Down Syndrome to Normal Births }\end{array}$ \\
\hline $15-19$ & $\ldots$ & $1 / 1250$ \\
$20-24$ & $\ldots$ & $1 / 1400$ \\
$25-29$ & $\ldots$ & $1 / 1100$ \\
$30-31$ & $\ldots$ & $1 / 900$ \\
32 & $\ldots$ & $1 / 750$ \\
33 & $1 / 420$ & $1 / 625$ \\
34 & $1 / 325$ & $1 / 500$ \\
35 & $1 / 250$ & $1 / 350$ \\
36 & $1 / 200$ & $1 / 275$ \\
37 & $1 / 150$ & $1 / 225$ \\
38 & $1 / 120$ & $1 / 175$ \\
39 & $1 / 100$ & $1 / 140$ \\
40 & $1 / 75$ & $1 / 100$ \\
41 & $1 / 60$ & $1 / 85$ \\
42 & $1 / 45$ & $1 / 65$ \\
42 & $1 / 35$ & $1 / 50$ \\
44 & $1 / 30$ & $1 / 40$ \\
45 and older & $1 / 20$ & $1 / 25$ \\
\hline & &
\end{tabular}

\subsection{PGD in King Faisal Specialist Hospital and Research Centre}

In 2012 and 2013 the King Faisal Specialist Hospital and Research Centre published new statistics for PGD in local newspapers, and based on these numbers we are going to build our facts and the importance of PGD (Graph1). The program of PGD in 2012 King Faisal Specialist Hospital and Research Centre has help 300 families to put an end for their suffering. Also the program op PGD result in 140 cases end with succeed pregnancy, and the ratio of success is $45 \%$ to be more than the global success ration which is $37 \%$. In addition the numbers of discovered diseases have change from 185 diseases in 2012 to 224 diseases in 2013 and the number therapeutic session have reach 300 sessions in 3013 and they aim to make it to 500 sessions every year. They reported that they help to prevent Cases of genetic diseases and the most important genetic diseases are thalassemia, sickle cell anemia, Cystic fibrosis and inherited metabolic disorders. 


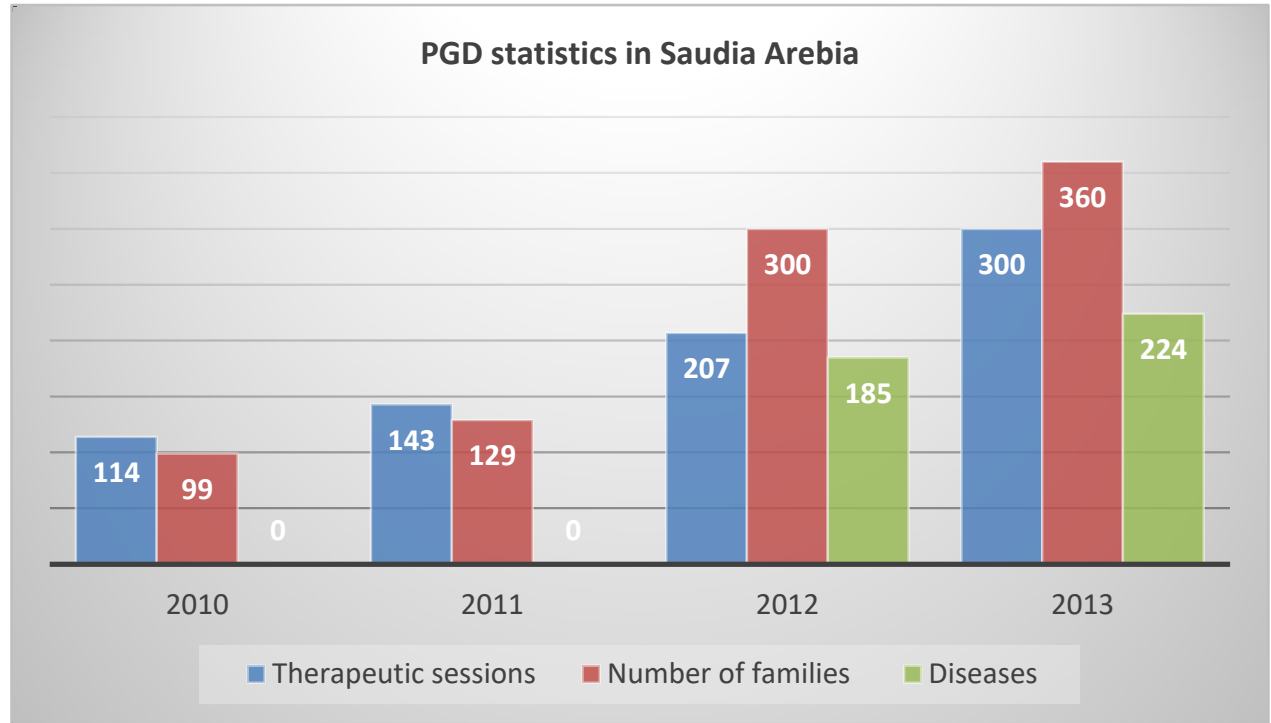

Figure 4. PGD Statistics in Saudi Arabia

\subsubsection{Down Syndrome}

Is a genetic disorder caused when mistake in cell division results in extra genetic material from chromosome $21 \&$ have 47 chromosomes, Trisomy 21 (About 95\% of all patients), Mosaic Down Syndrome (About $2 \%$ of Down syndrome patients) and Partial Trisomy 21 (Very rarely) Any one of three genetic variations can cause Down syndrome (Handarson, 2008).

\subsubsection{Sickle Cell Disease}

Sickle cell disease is an autosomal recessive disorder of hemoglobin in which the $\beta$ subunit genes have a missense mutation that substitutes valine for glutamic acid at amino acid 6 . The disease is most commonly due to homozygosity for the sickle cell mutation. As a result of these disorder the Glu6Val mutation in $\beta$ globin decreases the solubility of deoxygenated hemoglobin and causes it to form a gelatinous network of stiff fibrous polymers that distort the red blood cell, giving it a sickle shape (Handarson, 2008).

\subsubsection{Thalassemia}

Thalassemia are autosomal recessive anemias caused by deficient synthesis of either $\alpha$-globin or $\beta$-globin. A relative deficiency of $\alpha$-globin causes $\alpha$-thalassemia, and a relative deficincy of $\beta$-globin causes $\beta$-thalassemia. The pathogenesis of thalassemia arises from inadequate hemoglobin production and unbalance accumulation of globin subunits, which causes hypochromic and microcytosis (Handarson, 2008).

According to many studies in eastern region, the percentage of people suffering from sickle cell anemia is $28 \%$ and $30 \%$ for thalassemia in AL-Qatif. In addition, the number of people affected with sickle cell anemia in Eastern and southern Provinces is significant and more common than the rest (Alsultan, 2016). And the newspaper claimed that there is more than 25 thousand person suffer from G6PD anemia and more than 24 thousand suffer from sickle cell anemia, which cost the government more than 75 million 
R.S every year (Alsultan, 2016). And the percentage of people suffering from sickle cell anima in AL-Ahsa raised to $30 \%$ (Alsultan, 2016).

\subsection{Research Studies in Related PGD in Saudi Arabia and GCC}

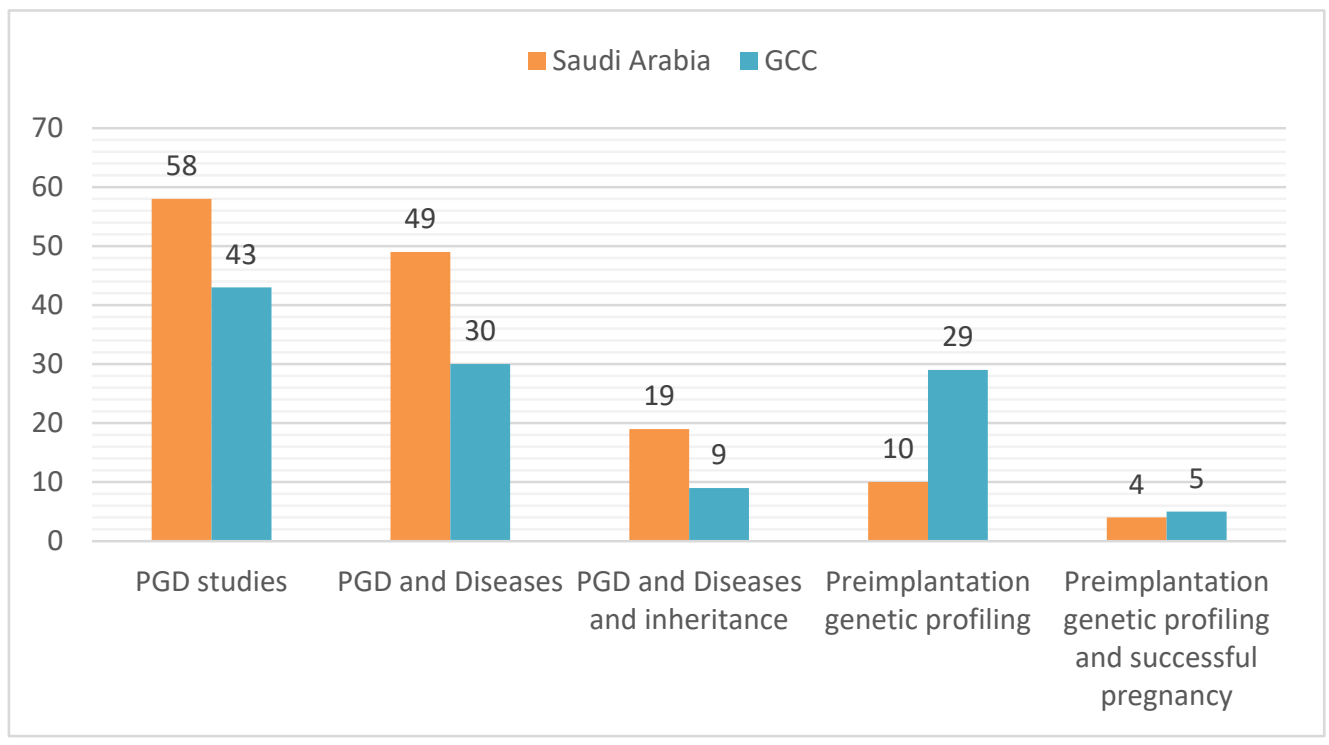

Figure 5. Numbers of Research about PGD in Saudi Arabia and GCC

Table 4. Number of Research in PGD Related to Disease

\begin{tabular}{lll}
\hline & Saudi Arabia & GCC \\
\hline PGD studies & 58 & 43 \\
PGD and Diseases & 49 & 30 \\
PGD and Diseases and inheritance & 19 & 9 \\
Preimplantation Genetic Profiling & 10 & 29 \\
Preimplantation Genetic Profiling and successful pregnancy & 4 & 5 \\
\hline
\end{tabular}

\subsection{Using PGD for X-Linked Diseases}

Hemophilia is X-linked disorders of coagulation caused by mutations in the F8 and F9 genes, respectively. Mutations of F8 cause deficiency or dysfunction of clotting factor VIII; mutations of F9 cause deficiency or dysfunction of clotting factor IX (Mastenbroek, 2011). Usually affects males, so we can do PGD for couples at risk of having a child with hemophilia A by gender selection (Figure 6) (Munne, 2009). Also Hemophilia A has an incidence of 1 in 5000 to 10,000 newborn males. Hemophilia B is far rarer, with an incidence of 1 in 100,000. 


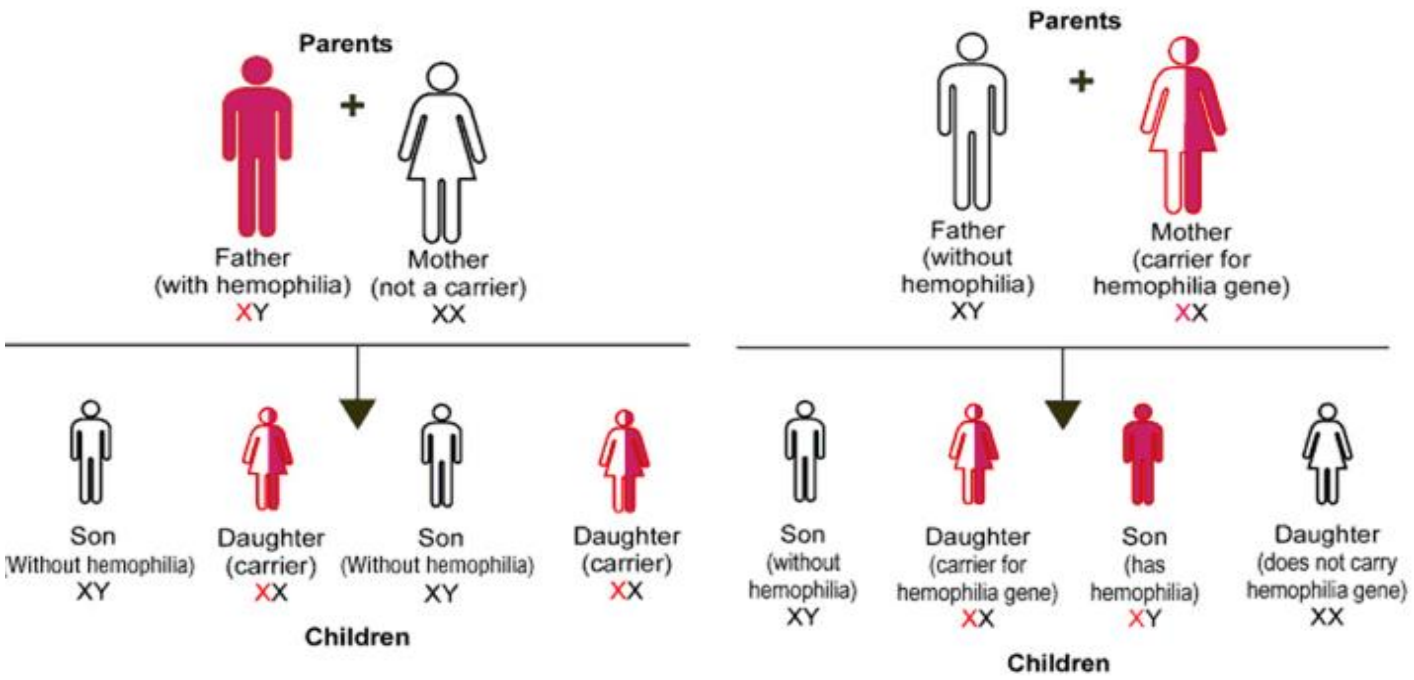

Figure 6. Genetic Inheritance of Hemophilia

There are two types of hemophilia: Hemophilia A: caused by defiance or absence in factor 8 (called Factor VIII also) in blood coagulation, and it is the most common form with $80 \%$ in all Hemophilia types. Hemophilia type B: caused by defiance or absence in factor 9 (also called Factor XI and Christmas Disease) in blood coagulation, and it's less common than type A (Table 5).

Table 5. Classification If Henophilia Based on the Severity

\begin{tabular}{ll}
\hline CLINICAL CLASSIFICATION AND CLOTTING FACTOR LEVELS \\
\hline Classification & $\%$ Activity (Factor VIII or IX) \\
Severe & $1 \%$ \\
Moderate & $1 \%-5 \%$ \\
Mild & $5 \%-25 \%$ \\
\hline
\end{tabular}

This Causes lifelong intellectual disability and developmental delays, and in some people it causes health problems.

Incidence of this dease in Riyadh to be 1 in 554 live births. The study scanned 23,261 consecutive live births to Saudi women over a period of nine years (1982-1991) to find 23 females and 19 males suffering from it. In the vast majority of these patients, the cause was non-disjunction trisomy 21.

\section{Discussion}

In order to be certain about our graduation project we did some searching for local and foreign statistics about PGD and how it help our society particularly, and we rely come out with some exciting result and ideas for PGD depending in many things. So to spurt our thoughts about PGD we added some statists 
to clarify our point of view for PGD as a therapeutic technique and not only that but also use it for organ Transplantation.

After we write above about PGD, in general we talk about result for some fields that utilize PGD technique like recurrent pregnancy loss and Down Syndrome Per Maternal Age (Pennings, 2003). And from the numbers we get we saw some good indicators for using PGD. In Advanced maternal age: Chromosomal Abnormalities (Table 2) we found that the percentage of having childe suffer from chromosomal abnormalities is increased with the age, so we can use PGD to decrease the percentage of having children with chromosomal abnormalities especially with 40 years and older women. Like Italian PGD study shows that the risk of miscarriage in women over 36 years old having PGD was 4\% whereas the risk of the same aged women having IVF without PGD was 20\% (Figure 7) (Ly, 2011).

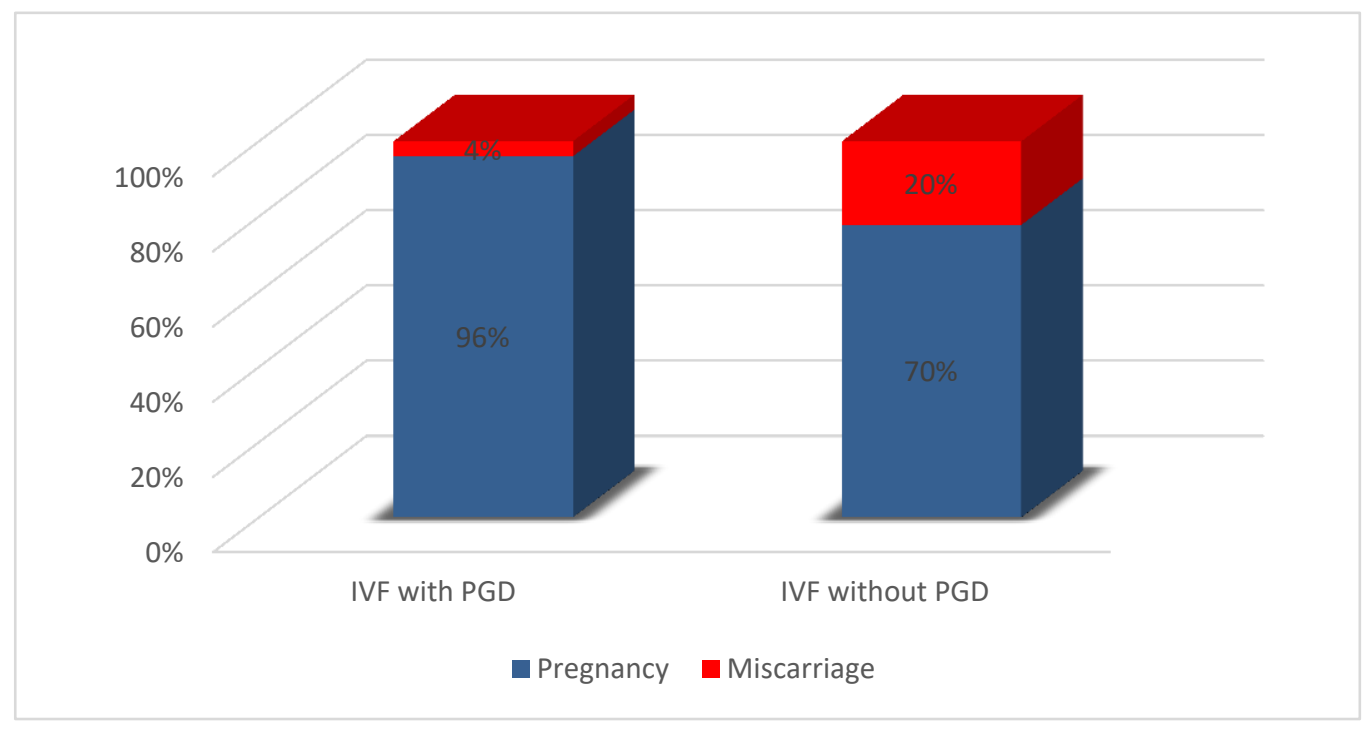

Figure 7. PGD in Italian Study Indicating Percentage of Successful IVF after Implantation

In addition, using PGD in Saudi Arabia has proved it benefit with remarkable accomplishments, which as we demonstrate it in Table 3 above. The PGD in King Faisal Specialist Hospital and Research Centre have helped many families in our region, and some of these accomplishments is the ratio of pregnancy, which is $45 \%$, and this percentage is more than the global ratio of pregnancy. Also the PGD program in King Faisal Specialist Hospital and Research Centre have given an end for more than 850 families suffer from inherited diseases.

Another aspect of PGD is using it to avoid X-Linked diseases by gender selection. And we have currently in Saudi Arabia some regions suffering from inherited Hemophilia cases especially in the south and east regions (Noble, 2008). And the reason we chose to talk about it is because many studies been in 2013, claiming that there is 2000 affected person in Saudi Arabia and it is costing the Saudi Ministry of Health 5 million R.S each year (Penning, 2003; Alsultan, 2016). And if we put using PGD in our minds in some of these cases as an option for treatment by gender selection or choosing best 
embryo it may give an end for this disease prevalence.

The other thing we want to talk about is how the PGD can be better economically and save a lot of money compering to some medicine or services for people suffer from inherited disease. The patients how suffer from down-syndrome cost the government Education Services around 65 million R.S every year, and the numbers of people affecting by these mutation is 150 thousand, which a huge number for Saudi Arabia is. Moreover, the cost of doing PGD is start from $\$ 4000$ to $\$ 8000$ in the US (Table 6) (Sermon, 2009), we could use it on people who have history with this mutation to save many money and produce healthy children without any mutation (Whittaker, 2011).

Table 6. IVF/PGD Cost in USA

\begin{tabular}{ll}
\hline & Average PGS IVF costs in USA \\
\hline IVF-ICSI Cost & $\$ 12,000$ \\
IVF medication costs & About $\$ 3500$ \\
Embryo biopsy cost & $\$ 1800$ \\
PGS test cost & $\$ 3500$ \\
FET cycle cost & $\$ 4000$ \\
\hline
\end{tabular}

We want to talk about the challenges and obstacles we had we start writing and searching about some statics or even new information we could use it in our project. The misery we had whenever search and did not find anything useful, the suffering we go through to find any static or even an official study we could rely on about genetic diseases is almost ZERO. We had to go through some very old news to find thing we could use like the Down syndrome article it is from 2003.

One last problem is about the annual statics book from ministry of health in Saudi Arabia, which shows almost nothing about genetics disease not even deaths nor effected newborn. And we guess the ministry of health should start to bot more affords in this point for at least better future for our children how will suffer from some disease they don't have any part in.

For the future of using PGD, we saw in increase of new field start to utilize PGD, like organ and bone marrow transplantation by chose the most embryos compatible with the recipient. In addition, we could use it for healthy families to gender selection because some families have only male or female children and this in our society cause many problems even sometimes caused divorce. Because some people think, the gender is depend on women and refuses to think that he is the reason for the childe gender. Moreover, for public awareness we chose to talk about PGD in Separated paper with Arabic and English languages if we have enough time. Because we believe, it may be easier for the people to understand PGD, if write about it in brief and use easier language and terms. 


\section{References}

Alsultan A., Jastaniah, W., Al Afghani, S., Al Bagshi, M. H., Nasserullah, Z., Al-Suliman, A. M., \& Alabdulaali, M. K. (2016). Demands and challenges for patients with sickle-cell disease requiring hematopoietic stem cell transplantation in Saudi Arabia. Pediatr Transplant, 20(6), 831-835. https://doi.org/10.1111/petr.12767

Asscher, E., \& Koops, B. J. (2010). The right not to know and Preimplantation Genetic Diagnosis for Huntington's disease. Journal of Medical Ethics, 36, 33. https://doi.org/10.1136/jme.2009.031047

Basille, C., Frydman, R., El Aly, A., Hesters, L., Fanchin, R., Tachdjian, G., ... Achour, F. N. (2009). Preimplantation Genetic Diagnosis: State of the art. The European Journal of Obstetrics \& Gynecology and Reproductive Biology, 145, 9-13. https://doi.org/10.1016/j.ejogrb.2009.04.004

Bellavia, M., Von Der Weid, N., Peddes, C., Jacquemont, S., Liebaers, I., Hohlfeld, P., ... DeZiegler, D. (2010). Preimplantation Genetic Diagnosis (PGD) for HLA typing: Bases for setting up an open international collaboration when PGD is not available. Fertility and Sterility, 94, 1129-1131. https://doi.org/10.1016/j.fertnstert.2009.11.007

Debrock, S., Melotte, C., Spiessens, C., Peeraer, K., Vanneste, E., Meeuwis, L., ... D’Hooghe, T. M. (2010). Preimplantation genetic screening for aneuploidy of embryos after in vitro fertilization in women aged at least 35 years: A prospective randomized trial. Fertility and Sterility, 93, 364-373. https://doi.org/10.1016/j.fertnstert.2008.10.072

Dumoulin, J. C., Bras, M., Coonen, E., Dreesen, J., Geraedts, J. P., \& Evers, J. L. (1998). Effect of $\mathrm{Ca} 2$ ?/Mg2?-free medium on the biopsy procedure for Preimplantation Genetic Diagnosis and further development of human embryos. Hum Reprod, 13(10), 2880-2883. https://doi.org/10.1093/humrep/13.10.2880

Handyside, A. H., Kontogianni, E. H., Hardy, K., \& Winston, R. M. (1990). Pregnancies from biopsied human preimplantation embryos sexed by Y-specific DNA amplification. Nature 19, 344(6268), 768-770

Hardarson, T., Hanson, C., Lundin, K., Hillensjö, T., Nilsson, L., Stevic, J., ... Bergh, C. (2008). Preimplantation genetic screening in women of advanced maternal age caused a decrease in clinical pregnancy rate: A randomized controlled trial. Human Reproduction, 23, 2806-2812. https://doi.org/10.1093/humrep/den217

Harper, J. C. (2001). Introduction. In J. C. Harper, J. D. A. Delhanty, \& A. H. Handyside (Eds.), Preimplantation Genetic Diagnosis (pp. 3-12). London, UK: John Wiley \& Sons.

Harper, J. C., \& Sengupta, S. B. (2012). Preimplantation Genetic Diagnosis: State of the art 2011. Human Genetics, 131, 175-186. https://doi.org/10.1007/s00439-011-1056-Z

Ly, K. D., Agarwal, A., \& Nagy, Z. P. (2011). Preimplantation genetic screening: Does it help or hinder IVF treatment and what is the role of the embryo? Journal of Assisted Reproduction and Genetics, 28, 833-849. https://doi.org/10.1007/s10815-011-9608-7 
Mastenbroek, S., Twisk, M., Van der Veen, F., \& Repping, S. (2011). Preimplantation genetic screening: A systematic review and meta-analysis of RCTs. Human Reproduction Update, 17, 454-466. https://doi.org/10.1093/humupd/dmr003

Munnè, S. (2009). Preimplantation Genetic Diagnosis for infertility (preimplantetion genetic screening). In J. C. Harper (Ed.), Preimplantation Genetic Diagnosis (pp. 203-229), Cambridge University Press, Cambridge.

Noble, R., Bahadur, G., Iqbal, M., \& Sanyal, A. (2008). Pandora's box: Ethics of PGD for inherited risk of lateonset disorders. Reproductive BioMedicine Online, 17, 55-60. https://doi.org/10.1016/S1472-6483(10)60332-X

Pennings, G., \& De Wert, G. (2003). Evolving ethics in medically assisted reproduction. Human Reproduction Update, 9, 397-404. https://doi.org/10.1093/humupd/dmg031

Sermon, K. (2009). Preimplantation Genetic Diagnosis for monogenic disorders: Multiple PCR. In J. C. Harper (Ed.), Preimplantation Genetic Diagnosis (pp. 237-246). Cambridge University Press, Cambridge.

Whittaker, A. M. (2011). Reproduction opportunists in the new global sex trade: PGD and non-medical sex selection. Reproductive BioMedicine Online, 23, 609-617. https://doi.org/10.1016/j.rbmo.2011.06.017 